\title{
END-RESULTS OF PLASTIC OPERATIONS ON THE KIDNEY PELVIS FOR HYDRONEPHROSIS
}

\author{
John K. Ormond, M.D., F.A.C.S.
}

Surgeon-in-Charge of the Division of Urology, Henry Ford Hospital; Extramural Lecturer (1937), University of Michigan

DETROIT, MICHIGAN

$\mathrm{F}$ ROM the early days of kidney surgery, there has been dissatisfaction among surgeons with nephrectomy as the invariable treatment of hydronephrosis. It, of course, relieved the symptoms, but frequently at the expense of functioning kidney tissue. When the opposite kidney was normal, this was of little consequence, but when the other kidney was absent or markedly diseased, it was disastrous.

So it is not surprising that quite early in the modern era attempts were made to devise plastic operations which would give an alternative to nephrectomy or permanent nephrostomy.

The first attempt of this kind was by Trendelenburg in $\mathrm{I} 886$, but it remained for Kuster, in I $89 \mathrm{I}$, to demonstrate that such operations could be successful, and he made the prediction that in time such operations would become the usual and accepted method of treatment for hydronephrosis. His success encouraged others to similar efforts, chief among them being Israel, Albarran, Riedel and Kümmell.

In 1908, Kroiss was able to find in the literature 102 instances of plastic operations on the pelvis, of which seventy were considered successful by the standards of the time, and three years later Weinberg collected forty nine additional cases.

During the next decade, in spite of the fact that there were reports of such operations from the clinics of Wildboltz, Gregoire, Simon, Goebell, Kroiss, Oehler, Gayet, Meyer, Schloffer, Zimmerman, Habler, and Mayo, this type of operation fell more or less into abeyance. The war may have had something to do with this. Be that as it may, in 1922 Frank and Glas, in reviewing the discussion of hydronephrosis which took place at the German Urological Congress in Vienna in $192 \mathrm{I}$, declared that up to that day nephrectomy was everywhere the standard operation for hydronephrosis.

About this time a new interest became manifest in hydronephrosis, its causes and treatment, and a new group of surgeons directed their interest toward the conservative treatment of hydronephrosis. This interest has persisted and has gradually widened.

In recent years there have been reports by Bailey, Bazy, Boerminghaus, Braasch, Cabot, Creevy, Eisendrath, Ferria, Foley, Frontz, Harris, Heckenbach, Henline, Hinman, Hryntschak, Krogius, Lubash, Mathe, Moore, Ormond, Papin, Peck, Priestly, Quinby, Roch, Sargent, Schaffhauser, Scholl, G. G. Smith, von Lichtenburg, Walters, Wildboltz, and Young.

Some of these have reported surprisingly large series of cases. Nevertheless, it remains true today, as it was fifteen years ago, that most hydronephrosis requiring operation, including such cases as might be considered fit subjects for plastic surgery, are treated by nephrectomy.

This fact argues for unfamiliarity on the part of the profession in general with the methods which can be employed; for the lack of confidence in plastic operations as a remedy for hydronephrosis; or possibly for a lack of agreement as to the preferable type of operation and lack of standardization of procedure. Moreover, it is objected that in some cases reported as successful, the evidence of success is inconclusive, and there seems to be an impression current 
that many cases at first apparently successful later come to grief through infection or trauma.

Therefore a review of the methods used, and a survey of end-results is timely. This should show what measure, and what proportion of success is possible; whether such success is permanent; what types of operation offer the best chance of success; what preoperative and post-operative measures are advisable or indispensable; and what adjuvant procedures are useful.

All plastic operations are of course based on the common sense theory that most hydronephrosis is due to mechanical obstruction, removal of which should remedy the condition to the extent of checking its progress and permitting as much restoration as is possible. There are undoubtedly cases of neurogenic dysfunction of the pelvis and ureter causing hydronephrosis, but they are the exception, and in the vast majority of cases of hydronephrosis, a mechanical obstruction can be demonstrated.

There are only four types of obstruction pertinent to this discussion. They are:

I. Compression or kink at ureteropelvic juncture caused by bands, either fibrous or vascular.

2. Stricture of the uretero-pelvic junction.

3. Kinking of ureter at the pelvis caused by ptosis or adhesions either inflammatory or congenital, and

4. Valve formation caused by high insertion of the ureter into the pelvis. This condition is caused by enlargement of the pelvis and itself becomes an obstructing factor and a cause of further pelvic enlargement.

We are not concerned with obstruction of the ureter proper, nor with calculous obstruction, though in any particular case of the latter, it cannot be taken for granted that the stone is the sole cause of obstruction, for on the one hand, the role of obstruction in the causation of stone is wcll known, and on the other, a stricture at the uretero-pelvic juncture may prevent the passage of a stone, which otherwise would have passed easily.

Conservative operations designed to remedy hydronephrosis are of two kinds:

I. Those which do not involve incision into the pelvis or ureter, and

2. The true plastics.

Those which do not involve incision into the urinary passages are those in which the only procedures are some form of fixation of the kidney, or the sectioning of a fibrous or vascular band.

Nephropexy needs no prolonged discussion. Much has been written about it, and several methods have been devised. After falling into disrepute for many years due to its indiscriminate use, it has gradually been reestablished as a useful procedure in a limited class of cases, with very definite indications for its employment.

Hydronephrosis may be caused by bands - either fibrous or vascular - which constrict, compress, or kink the ureter or the uretero-pelvic juncture. Fibrous bands may of course be sectioned freely. The vascular bands are the more common and such a band may contain an artery or a vein or both. Veins may be sectioned freely, but some years ago Hinman and Hepler published some work showing that such aberrant arteries were usually end arteries and that their section would cause infarction of a portion of the kidney, which if the vessel were large and supplied a large portion of the kidney, would be undesirable and might be disastrous. Some recent work goes to show that these are not invariably end arteries, but extensive necrosis, sometimes leading to secondary nephrectomy following section of such arteries has been reported (Christensen, Belt, Ball-Guling, Frank and Glas, Granhahn, Lassio, Essendrath and Wolfram). Heckenback reports a septic icterus resulting from an infected infarct, and Marion a temporary renal fistula due to partial renal necrosis. Wildboltz observed long continued albuminuria and Young reported important reduction in function. 


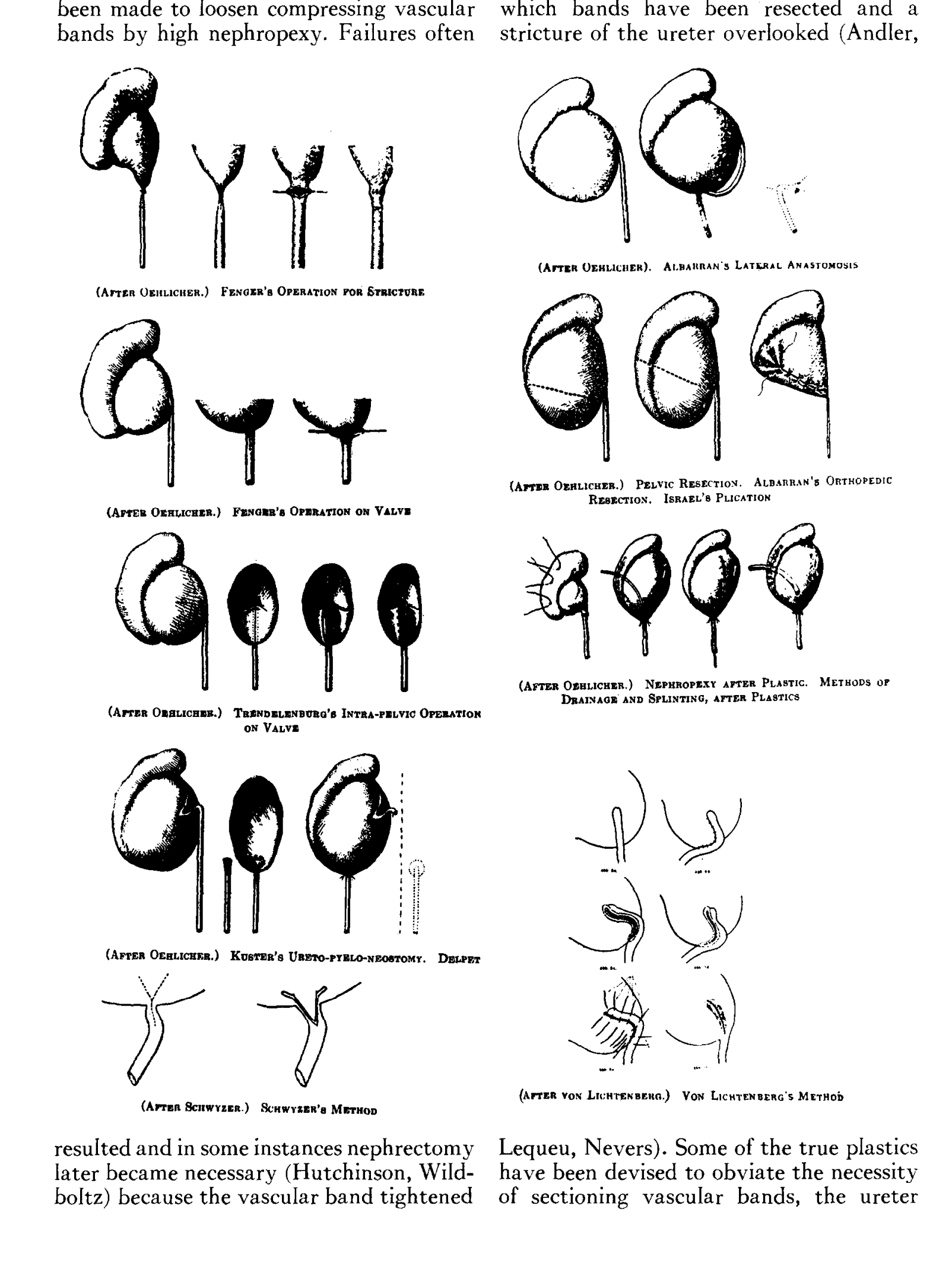


being sectioned instead, and reimplanted into the pelvis on the other side of the band.

The true plastic operations can be divided into four types: the Fenger (Heinecke-Mikulicz) operation; ureteropyeloplasty; reimplantation of the ureter into the most dependent portion of the pelvis; and resection and plication.

The Fenger operation is like the Heinecke-Mikulicz operation on the pylorus and consists in incising a stricture and suturing in the reverse direction.

Several kinds of ureteropyeloplasties have been devised, the best known being those of Albarran, von Lichtenburg, Schwyzzer, and Foley. Albarran's operation consists in a lateral anastomosis between pelvis and ureter. Von Lichtenburg's operation resembles the Finney pyloroplasty, Schwyzzer's original operation consisted in a $\mathrm{Y}$ incision-the $\mathrm{v}$ being in the pelvis and the stem down the ureter. The $\mathrm{v}$ flap is brought down to the lower end of the stem and sutured there, thus widening the uretero-pelvic juncture.

Foley's operation is a modification and improvement of Schwyzzer's. He has moved the longitudinal incision of the ureter to its lateral aspect, that is, to the surface next the kidney, and extended the $\mathrm{v}$ incision, one arm to the anterior and one to the posterior aspect of the pelvis, so that the sutures bring the opening of the ureter to a more dependent position. This operation is now known as the Foley y plastic.

Reimplantation of the ureter may be done in three ways: in one a small collar of pelvic wall is excised with the ureter and reimplanted into the pelvis; in the other two, the ureter is sectioned and reimplanted into the pelvis, either suturing the pelvic wall around it like a cuff, or suturing the cut edges in accurate apposition.

Rescetion and plication require no explanation.

Conservative treatment of hydronephrosis is imperative when there is a solitary kidney or both kidneys are hydronephrotic. Here plastic surgery may be the only alternative to permanent nephrostomy and the surgeon must know what plastic operation offers the best chance of success. Conservatism is optional when one kidney is normal; and in this case the surgeon wishes to know not only which is the easiest and most promising, but whether, taking everything into consideration, the attempt is worthwhile.

The ultimate criteria of the success of plastic operations for hydronephrosis are relief of symptoms and conservation or restoration of function. Elimination of infection and anatomic restoration are desirable but not essential.

In the earlier days function tests were not possible - nor were pyelograms. Later, function tests were devised and pyelography came into use, but required cystoscopy which made it a disagreeable and cumbersome procedure. Now however, in intravenous urography, we have a simple and convenient method of measuring both functional and anatomical restoration. Clinical relief of symptoms in the presence of a normal kidney on the other side is not sufficient ground for claiming success -for as Cumming pointed out recently, renal atrophy sometimes takes place in such cases, and the symptomatic relief may be accompanied by destruction of the kidney just as complete as if nephrectomy had been performed.

Only through a consideration of a large number of cases, especially of those which have been observed over a long time, can we draw conclusions regarding the possibility of success, the suitability of operations, and regarding the validity of objections which have becn raiscd.

In the literature there are recorded a few isolated cases which have been demonstrated by autopsy, or otherwise, to be successful many years after operation. Bazy demonstrated a kidney with good drainage and good parenchyma twentyfour years after uretero-pyelo-neostomy. Hartman had a good result from a Fenger operation after twenty one years. Legueu, fifteen years after uretero-pelvic anastomosis found the kidney functioning and drain- 
ing well. Wildboltz used Kuster's operation on a large infected traumatic hydronephrosis and twenty years later it still showed some function, and in the meantime had been symptom free. In another instance he performed a Fenger operation on a hydronephrosis the size of a child's head, and found sixteen years later, that there was only slightly less function on this side than on the other. In two other cases there were good results sixteen years after pyeloneostomy. Von Lichtenburg, sixteen years after pyelo-uretero-neostomy, removed the kidney for carbuncle and found it functioning. He also had another case in which the other kidney was removed sixteen years later, and the patient survived.

These isolated reports surely prove that permanent success of plastic operations is possible, but indicate nothing as to the frequency of success. A review of the results obtained in a long series of such attempts by many different operations is necessary to the appraisal of the chances of success, the determination of the indications and contra-indications for operation, and for decision as to the best methods of operation.

The longest series is reported from the Mayo Clinic. Walters, Cabot, and Priestly report seventy-one plastic operations in sixty four patients, with fifteen secondary nephrectomies and two deaths. All these were done in the past few years, and in 89 per cent there were satisfactory follow-up reports. They regard 70 per cent of their results as at least satisfactory, and report diminution in the size of the pelvis in a large portion of their patients. They favor resection of the pelvis and reimplantation of the ureter into the portion of the pelvis remaining, though they have used other methods. They have used the splinting catheter and nephropexy in most instances.

From the clinic of von Lichtenberg and Heckenbach, sixty nine conservative operations for hydronephrosis are reported, with fifty two successes, at the end of a year and a half. There was one death. These figures, however, require modification, for many of their conservative operations were not plastic operations on the pelvis in the sense used here. On scrutiny we find twenty two true plastics, the other operations being heminephrectomy, resection of vessels, dilatations of the ureter, etc. Von Lichtenberg recommends excision of the twelfth rib for exposure, if necessary, and has chiefly favored the uretero-pyeloplasty known by his name, or resection of the pelvis with reimplantation of the ureter into the remaining portion, suturing the pelvic wall about the ureter like a cuff.

Wildboltz reports fourteen plastic operations, with one failure. His observations cover many years and include reimplantations, uretero-pyeloplastics and Fenger operations. He favors preliminary nephrostomy in the presence of infection.

Quinby in I929 had sixteen cases, of which two were unsuccessful. Most of these were ureteral reimplantation about a vascular band. Two were Fenger operations-moth failures. His cases have been observed over many years and show satisfactory results. He does not use a splinting catheter, sutures the ureter to the pelvis with accurate apposition of the edges and advises that infection be treated before operation.

Foley reports twenty one $\mathrm{Y}$ plastic operations on nineteen patients with no failures and two deaths. All of his operations must have been in cases of stricture of the uretero-pelvic juncture, or of high implantation of the ureter. He uses nephropexy when indicated and closes his ureteral and pelvic incision with a large number of fine cat gut sutures placed close together. He has followed some of his patients for ten years.

Creevy reports ten cases; nine y plastics with one failure requiring nephrectomy, and one successful case of section and reimplantation of the ureter. His observations are all of comparatively short duration. He has noted diminution in the size of the pelvis and clearing of infection, favors a splinting catheter and catheter drainage of the pelvis. 
Sargent reports twelve cases with one poor result in a $Y$ plastic. He has used the Fenger operation three times. He emphasizes the possibility of anatomic restoration.

T. D. Moore has twelve cases observed over several years with two unsatisfactory results.

Hryntschak, in 1936, reported thirteen cases with two unsatisfactory results. Most of his patients had been observed less than four years. He lays stress on adherence to the general principles of all plastic surgery as essential to success.

To sum up then, we have here reports of one hundred and ninety-one cases with a high rate of success. Of the 169 cases in which there is definite information, there were only four deaths and twenty-five failures, a death rate of 2.3 plus per cent, and a failure rate of $\mathrm{i} 4.8$ minus per cent.

In addition to these longer series are some shorter series in which the results varied a good deal.

G. G. Smith, in 193I, reported six cases with one secondary nephrectomy and one questionable result.

Henline, in 1935, reported on seven cases with two failures and one death from thyroid crisis. Most of the operations reported by him were of the Fenger type, and most of them had been observed for only a short time.

Patch has reported a short series in which he implanted the ureter with a collar of pelvic tissue, and regards his results as satisfactory.

Kimbrough, in 1935, described six cases, all successful, though most of them were observed for only a short time. He used the splinting catheter.

Schaffhauser, in 1936 , reported five cases observed less than four years-all satisfactory. He most often used the Fenger operation. He believes infection is a contraindication to operation.

In 1936, I reported five failures, two of which were converted into successes by second operations; two of which required secondary nephrectomy; and one of which continued to have symptoms. Since then, one patient who had been symptom free for seven years has returned with recurrence of symptoms, similar to those of which he originally complained, but which have not yet been investigated.

Scattered through the literature, in discussions, etc., are references and allusions to isolated cases and short series with varying success. In this country Morrissey and Randall speak unfavorably of the operation-as do Marion, Cifuentes and Allesandri in Europe.

\section{SUMMARY AND COMMENT}

It is evident that not only is it possible for plastic operations to be successful, but that success has actually attended by far the greater number of such operations performed by the group of surgeons who have the most experience with this type of surgery. This has not been true to the same extent of the occasional operator.

When failures occur, they are recognizable early, usually immediately and certainly within a year, with rare exceptions. I have had one apparent recurrence after seven years, and Quinby reports one after a similar period, but they are the exceptions.

The danger to life is not great. It is safer than nephrectomy. Heckenbach reports from Von Lichtenburg's clinic a series of forty-six nephrectomies for hydronephrosis with one death. In the series cited earlier, there were only four deaths in 174 operations.

Infection as an obstacle to plastic surgery has been overemphasized. It must be respected and treated both before and after operation, often by preliminary nephrostomy and always by post-operative drainage, but instances of healing in spite of continuing infection, and failure to remedy obstruction are on record. I have one such case. Deep seated infections of long standing may persist along with relief of symptoms and improvement in function.

In successful cases there will be relief of symptoms, some functional restoration, 
and there may be considerable anatomic restoration.

Interruption of the nerve and blood supply by section of the ureter seems of little consequence. Those who have practiced section of the ureter with reimplantation, have had no morc failures than those who preferred uretero-pyeloplasty.

The evidence seems to be hostile to the theory of renal counterbalance, unless it may be construed as evidence in its favor that solitary kidney or bilateral hydronephrosis seem to offer the most favorable opportunity for successful plastic operation.

There is difference of opinion as to the value of resection or plication of the pelvis. On one hand, it is argued that no resection or plication can restore power to an overstretched and atrophied pelvic muscle; on the other hand, it is admitted that either procedure will diminish the residual reservoir, which may be worthwhile. On the whole, the evidence seems to favor resection, even though it adds to the length of operation and to the amount of manipulation involved. I have tried it just once, in a case in which the ensuing failure could not be blamed on this procedure.

The balance of opinion and the evidence is rather strongly against the Fenger operation. It is a seductive procedure- it looks simple, but in reality it requires finer judgment than the other operations. If the incision through the stricture is a shade too long, or if the stricture is long, suturing in the reverse direction may cause puckering and a reformation of the obstruction it set out to remedy. It seems to have been a favorite with those who have undertaken plastic operations only once or twice and this may explain their discouragement with plastic surgery. Nevertheless, there are those who feel that this operation has a place, and who have used it with satisfaction. Two of my failures were with this type of operation.

The operations of ureteral reimplantation and uretero-pyeloplasty seem equally successful in the hands of those who use them. My own preference is for reimplantation, for it does not necessitate the section of a vascular band, and is as applicable to stricture and high ureteral implantation as is uretero-pyeloplasty. It seems to me simpler; to require less manipulation; and to make less demand on the judgment. This however, is only a personal opinion, and certainly the results obtained by Foley and Creevy speak for themselves.

Three methods of reimplantation have been mentioned: one in which a small collar of pelvic tissue is excised with the ureter and reimplanted into the pelvis; the second in which the ureter is allowed to project into the pelvis for a short distance, the pelvic wall being sutured about it like a cuff; and the third in which the ureter is sutured to the pelvic opening with accurate apposition of the cut edges. The evidence of their value is conflicting, and it is possible to give only a personal preference. I prefer the third. It seems to me that it would be possible to overlook a stricture or valve at the juncture, in the first method, and that it would be possible to create a valve by the second. This latter has been reported. However, von Lichtenburg has used the second method with satisfaction and it is possible that Lubash's recently described method may eliminate danger of valve formation. I have had two failures using the second method, remedied later by reoperation with suture in accurate apposition. This successful result, however, may have been due to the long continued splinting of the ureter.

There are three subsidiary procedures concerning the use of which there is little difference of opinion. Nephropexy is favored by most surgeons whenever indicated; post-operative pelvic drainage is favored by nearly all operators; and the use of the splinting catheter in the ureter is almost universal. Quinby argues against it, and his record of success gives his opposition great weight, but the balance of opinion is against him. In this connection, a very striking case is reported by McArthur, in which a hiatus in the ureter 
was bridged around a splinting catheter which was left in place for a long time, with complete restoration of the ureter.

\section{CONCLUSIONS}

In arriving at final conclusions, all the above facts, opinions, and arguments must be considered, and in addition due weight must be given to the following: the special importance of conservation of renal function in certain classes of patients-particularly in young women in the child bearing age; the fact that with one good kidney, the importance of the other varies inversely with the age or directly with the life expectancy; and the factor of expense and loss of time.

Giving all of these their proper weight, it seems to me that the following final conclusions are justified:

I. With the solitary kidney or with bilateral involvement, conservatism is mandatory and plastic surgery should be employed. Resort can be had to permanent nephrostomy if this fails.

2. In the presence of one good kidney (and this should not be considered good unless the pyelogram is normal, the function excellent, and no infection is present) if in the involved kidney there is function worth preserving:
$A$. Plastic surgery is indicated in children and young adults, espe- cially in young women in the child-bearing age.

$B$. Nephrectomy is the preferable procedure after the age of 50 .

$C$. In the middle years, decision should be based primarily on the experience of the surgeon in this type of surgery; and secondarily, on the financial status of the patient; for failure means increased expense and a lengthened period of disability - matters of serious import to the vast majority of patients.
3. If plastic surgery is decided on, one of the proven methods of ureteropyeloplasty, or section and reimplantation, should be chosen, rather than the Fenger operation.

\section{REFERENCES}

Andler, R. Pathologic Significance of Accessory Renal Vessels. Ztscb. f. Urol. Clin., 19: 305-341, 1926.

Bailey, Hamilton. Nephro-ureteral Anastomosis. J. Urol., 20: 103-107 (July) ı928.

BraAsch, W. F. Clinical Notes on Hydronephrosis. Interstate J. J., 2 I : I 180-1 188, 1914.

Bazy, P. De I'Uretero-pyelo-neostomie. Ses Resultats Éloignés. Bull. Mem. Soc. Nat. de Cbir., 54: 313320 (March 3) 1928.

Colby, Fletcher H. Hydronephrosis from Aberrant VesseIs. New England J. M., 205: 1042-1043, 193 I.

Creevy, C. D. Operative Treatment of Hydronephrosis. Surgery, 1: 228-238 (February) 1937.

Cumming, R. E. and Schroeder, C. F. Renal Atrophy. J. Urol., 37: 407-437 (April) I937.

Eisendrath, D. N. Hydronephrosis due to Obstruction of Renal Pelvis by One of Two Main Renal Arteries. J. Urol., 24: 173-185 (August) 1930.

Fey, Bernard. Resultate de Douze Interventions pour Syndrome Douloreaux d'Hydronephrose. Role Preponderant des Arteries Anormales. Arcb. Urol. de la Klin. Necker, 5: 193-227, 1928.

Foley, Frederic E. B. A New Plastic Operation for Stricture at the Uretero-Pelvic Junction. Thirty fourth Annual Meeting, American Urological Association, June 29, 1937.

Geraghty, J. T. and Frontz, W. A. A Study of Primary Hydronephrosis. J. Urol., 2: 161-209, 1918.

Heckenbach, W. Ein Beitrag zur Palliative Chirurg. Therapie der Hydronephrose. Ztscb. fur Urol Cbirurgie, 29: $33^{6}-389$, 1930. (With additional references.)

Heckenbach, W. Zur Frage der Behandlung der Verstopfungsnieren durch Akzess. Gefässe. Ztsch. f. Urol. Cbir., 32: 149-156, 1931.

Harris. The problem of non-calculous ureteropelvic obstruction. Ann. Surg., 102: 1050-1057 (December) 1935 .

Henline, R. B. The cause and treatment of non calculous ureteropelvic obstructions. J. Urol., 34: $584^{-}$ 609 (December) 1935.

Herbst, R. H. and Polkey, H. J. Fenger's ureteroplastic operation. J. Urol., 22: 23-3 I (January) 1930.

Hinman, F. Renal counterbalance. Tr. Amer. Ass. Gen. Urin. Surg., 1 5: 241, 1922.

Hinman, F. Significance of Renal counterbalance in surgical treatment of renal lesions. J. A. M. A., 94: I 207-12 I0 (April) 1930.

Hinman, F. Principles and Practice of Urology. Phila. and London, W. B. Saunders Co., 1935.

Hinman and Butler, O. W. Repair in Hydronephrosis. J. A. M. A., 81 : 2021-2023, 1923.

Hryntschak, TH. Ueber Nierenbeckenplastiken bei Hydronephrosen. Wiener Klin. Woch., 49: 620-62I (May 1 5) 1936. 
JoNes, Daniel Fiske. Intermittent hydronephrosis. Boston M. S. J., 90: 520-539, 582-588,613-622, 1909 .

Joelson, J., Beck, C. S. and Moritz, A. R. Renal counterbalance. Arcb. Surg., 49:503-509 (October) 1929.

Judd, E. S. Surgery of the Ureter. Minnesota Med., 4: 597 (October) r921.

Krogius, A. Doppelseitige Hydronephrosen verinsacht durch angeborene Verengerung der beiden oberon Ureterenden. Ztscb. f. Urol., 24: 333-342, 1930.

Krogius, A. Ueber termino-laterale Pyelo-Ureterostomie. Zentralbl f. Chir., 54: 1034-1036 (April 23) 1927.

Kroiss, F. Uber de plastischen Operationen am Nierenbecken und oberen Hainleite abschnitt bei den Retention geschwulsten der Niere. Beitr. \%. klin. Chir., 58: 428-549, 1908.

Kummer, R. H. Resection for Hydronephrosis. $J$. d'Urol., 13: 425-432 (June) 1922.

Kummer, R. H. Controle eloigne d'un cas d'hydronephrose haite, par operation conservatrice. $J$. d'Urol., 26: 567-571 (December) 1928.

LAsıo, G. B. Rapport Interval Urologenkongress. Madrid, I930.

Lasio, F. B. Etiologie et traitement des hydronephroses. J. d'Urol., 30: 29-33 (July) 1930.

LEGUEU, F. La motricité du bassinet étudice sur la rein fraichement nephrectomise. $J$. d'Urol., 24: 6I-67 (July) I 927.

Lubash, Samuel. Uretero-pyeloneostomy for Hydronephrosis. A new technique. J. Urol., 34: 222-230 (September) I 935.

Lubash, Samutl. Ureteropyeloneostomy for Hydronephrosis. Thirty-fourth Annual Meeting, American Urological Association, June 29, I937.

MCARThur, L. L. New and simple repair of ruptured or strictured ureters. Surg. Gynec. and Obst., I 2 : 719-72 I (December) 1925.

Marion, G. A propos de I' hydronephrose par vasseau anormal. Bull, et mem Soc. de Cbir. de Paris, 49: 574, 1923.

MAthe, C. P. Role of aberrant vessels in production of hydronephrosis. J. Urol., 19: 2 1 -240 (March) 1928.

MoOre, T. D. Conservation of renal tissue. Urol. er Cut. Rev., 39: 393-398 (June) 1935.

Moore, T. D. Discussion, June 29, 1937. Thirty-fourth annual meeting, American Urological Association.

Oehlecker, F. Ueber die Behandlung der Hydronephose. Ztscb. f. Urol Chir., 10: 1-46, 1922. (With additional references.)

Ombredanne. Report of Case. Bull. Mem. Nat. de Cbir., 54: No. 12, 3 19 (Feb. 22) 1928.

Ormond, J. K. Plastic Surgery of the Ureter. J. Urol., 25: 117-143 (February) 1931. (With additional references.)

Ormond, J. K. Unsuccessful Plastic Operation for Hydronephrosis. J. Urol., 36: 5 I 2-531 (November) 1936.

Papin, E. Dequelques opérations conservatrice dans les hydronephroses. Bull. et mem. Soc. Bat de Cbir., 54: 500-524 (April 7) ig28.

Patch, F. S. Conservative Plastic Surgery in Treatment of Hydronephrosis Associated with Aberrant Vessels. Brit. J. Urol., I: 373-379, I929.
Pracock, Alexander Hamilton. Ilydroncphrosis, Etiology and Treatment. J. Urol., 37: 63-73 (January) I937.

Peck, C. H. Non-calculous Obstruction of the Upper Ureter. Ann. Surg., 62: 252-255, 1915.

Peck, C. H. Treatment of Obstruction of the Upper Ureter and Early Hydronephrosis. Ann. Surg., 80: 3; 260-266 (February) 1926.

Quinby, W. C. Factors Influencing Operative Procedure in Hydronephrosis. J. A.M. A., 93: 1709I 710 (November 30) 1929.

Quinby, W. C. Dynamics of the Ureter. Trans. Amer. Assoc. Gen. Urin. Surg., 21: 383-392, 1928.

Quinby, W. C. Plastic Surgery of the Renal Pelvis. J. A. M. A., 89: 841-844 (September 10) 1927.

Quinsy, W. C. Factors Influencing the Operative Treatment of Hydronephrosis. Thirty-fourth Annual Meeting, American Urological Association, June 29, I937.

Randall, Alexander. The Surgery of the Upper Ureter. J. Urol., 33:552-559 (June) 1935.

Sargent, J. C. Pyelo-ureteroplastic Correction of Enormous Hydronephrosis. J. Urol., 20: 613-6I4 (November) I928.

SARGENT, James C. The Conservative Management of Hydronephrosis. Wisconsin M.J. 35;953 959 (December) 1936.

SARgent, James C. Conservative Surgery in Hydronephrosis. Thirty-fourth Annual Meeting, American Urological Association, June 29, 1937.

Schaffhauser, F. Conservative Plastic. Deutcb Zeit. f. Cbir., 244: 367-372, 1935 .

Schaffhauser, F. Plastische Operationen bei Hydronephrose. Brun Beitr. z. Klin. Cbir., 163: 1-18 (January) 1936. (With additionaI references.)

Schwyzzer, A. New Pyeloureteral Plastic for Hydronephrosis. S. Clin. Nortb America 3: I $44^{1-1} 44^{8}$ (October) 1923.

Smith, G. G. Plastic Surgery Kidney and Ureter. New England J. M., 204: 297-3 I4, Feb. I 2, 193 I.

Viollet, M. (Limoges). A propos du Traitment Chir. des Hydronephroses Bilaterales. Bull. de la Soc. Francais d. Urol., No. 3, 126-137 (March 16) I931.

Von Lichtenberg, A. Plastic Surgery of the Renal Pelvis and Ureter. J. A. M. A., 93: 1706-1708 (Nov, 30) 1929.

Von Lichtenberg, A. Tech. zur Ureteropyeloanastomosis. Ztscb.f. Urol. Cbir. (1921); Abst.J. A.M.A., 27: 743,1921 .

Von Lichtenberg, A. Fortschutte und Ausbliche der Nierenchirurgie in den lestzten zehn. Ztsch. $f$. Urol., 16: 301-308, 1922.

Walters, Waltman. The Conservative Treatment of Hydronephrosis by Resection of the Renal Pelvis and Other Plastic Operations. J. Urol, 29: $121-$ 134 (February) 1933.

Walters, Waltman. Restoration of Renal Function following Removal of Obstructing Lesions. Ztsch. f. Urol. Chir., 36: 264-273, 1933.

Walters, Waltman. Plastic Operations. Proc. Staff Meet. Mayo Clin., ro: 529-533 (August 21) 1935 .

Walters, Waltman and Brown, A. E. A Clinical and Urologic Study Seven Years following Bilateral Resection of the Renal Pelvis for Bilateral Hydronephrosis. Staff Meet. Mayo Clin., I I: $43^{2-440}$ (July 8) 1936. 
Walters, W. and BraAsch, W. F. Urinary Obstruction and Hydronephrosis Resection of Renal Pelvis, Kidney and Ureter-Report of Cases. J. A. M. A., 93: 1710-I715 (November 30) 1929.

Walters, W. and Braasch, W. F. Bilateral Resection of Hydronephrotic Renal Pelvis; ligation of Anomalous Renal Artery with Polycystic Kidney; Heminephrectomy: ureteropyeloneostomy. Proc. Staff Meet. Mayo Clin., 4: I6I (May 22) 1929.

Walters, Waltman, and Braasch, W. F. Resections of the Renal Pelvis and Other Plastic Operations for Hydronephrosis. End Results in 13 cases. Surg. Gynec. and Obst., 55: 508-517 (October) 1932.

Walters, Waltman and Braasch, W. F. Results Three Years after Resection of the Renal Pelvis. Report of a Case. Proc. Staff Meet. Mayo Clin., 8: $691-\left(x_{94}\right.$ (November 15) 1933.
Walters, Waltman, Cabot, Hugh and Priestly, James T. Operative Results in Hydronephrosis. Thirty-fourth Annual Meeting, American Urological Association, June 29, 1937.

Weinberg, F. Plastische Operations am Nierenbecken. Beitr. z. klin. Chir., 72: 722-740, 1909.

Wildboltz, Hans. Damfolge organerhallender plastischer Operationen bei Hydronephrose. Ztsch f. Urol. Cbir., 31: 63-88, 193 I.

Wildboltz, H. Report of ${ }_{14}$ Cases of Plastic Operation for Hydronephrosis. J. d'Urol., 20: 423, 1925.

Wilhelm. Seymour F. and Blinick, George. Pelvic Plication in Treatment for Hydronephrosis. Am. J. Surg., 35: 90-98 (January) I 937.

Winsbury-White, H. P. The Pathology of Hydronephrosis. Brit. J. Surg., 13: 247 279, 1925.

Young, H. H. Practice of Urology. 2: 301, Phila. and London, W. B. Saunders Co., 1926 .

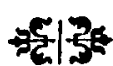

IN 1879 Neisser discovered the gonococcus. Nitze introduced cystoscopy. In I88 I Hahn performed nephropexy. In I905 Schaudinn discovered the parasite of syphilis.

From-Garrison's "History of Medicine." 